Insight, part of a Special Feature on Understanding the Vulnerability and Sustainability of Urban Social-Ecological Systems in the Tropics: Perspectives from the City of San Juan

\title{
The green areas of San Juan, Puerto Rico
}

\author{
Olga M. Ramos-González ${ }^{1}$
}

\begin{abstract}
Green areas, also known as green infrastructure or urban vegetation, are vital to urbanites for their critical roles in mitigating urban heat island effects and climate change and for their provision of multiple ecosystem services and aesthetics. Here, I provide a high spatial resolution snapshot of the green cover distribution of the city of San Juan, Puerto Rico, by incorporating the use of morphological spatial pattern analysis (MSPA) as a tool to describe the spatial pattern and connectivity of the city's urban green areas. Analysis of a previously developed IKONOS 4-m spatial resolution classification of the city of San Juan from 2002 revealed a larger area of vegetation (green areas or green infrastructure) than previously estimated by moderate spatial resolution imagery. The city as a whole had approximately $42 \%$ green cover and $55 \%$ impervious surfaces. Although the city appeared greener in its southern upland sector compared to the northern coastal section, where most built-up urban areas occurred (66\% impervious surfaces), northern San Juan had 677 ha more green area cover dispersed across the city than the southern component. MSPA revealed that most forest cover occurred as edges and cores, and green areas were most commonly forest cores, with larger predominance in the southern sector of the municipality. In dense, built-up, urban land, most of the green areas occurred in private yards as islets. When compared to other cities across the United States, San Juan was most similar in green cover features to Boston, Massachusetts, and Miami, Florida. Per capita green space for San Juan (122.2 $\mathrm{m}^{2} /$ inhabitant) was also comparable to these two U.S. cities. This study explores the intra-urban vegetation variation in the city of San Juan, which is generally overlooked by moderate spatial resolution classifications in Puerto Rico. It serves as a starting point for green infrastructure mapping and landscape pattern analysis of the urban green spaces within the city of San Juan. The effectiveness of research and city planning will be further enhanced as a result of this type of finer-scale urban cover exploration.
\end{abstract}

Key Words: green areas; green infrastructure; morphological spatial pattern analysis (MSPA); spatial pattern analysis; urban forests; urban green area characterization; urban vegetation

\section{INTRODUCTION}

Cities are increasingly the focus of attention in a number of traditional and emerging disciplines that study social-ecological systems with an aim to understanding their structure, how they function, and their capabilities to support people (Breuste et al. 1998, McDonnell et al. 2009, Niemelä 2011). Describing the spatial coverage of urban green areas and understanding their structure, composition, and functioning has also emerged as a critical component for understanding cities, irrespective of the field of study or the particular approach taken to understand and influence their functioning (McDonnell et al. 2009, Niemelä 2011). Furthermore, green areas, also known as green infrastructure or urban vegetation, are vital to urbanites because of their critical roles in mitigating urban heat island and climate change, and for their provision of multiple ecosystem services and aesthetics (Dige 2011, Hudeková 2011, Science for Environment Policy 2012). Accurate estimates of green area cover and assessments of the types of green area systems in a city are critical for city metabolism calculations, quantitative assessments of ecological functioning of cities, as well as evaluation of ecosystem services to people. City planning is more effective with a more accurate understanding of the spatial extent and distribution of green areas (Breuste et al. 2008).

With this study, I provide a high spatial resolution snapshot of the green cover distribution of the city of San Juan, Puerto Rico, by incorporating the use of morphological spatial pattern analysis (MSPA) as a tool to describe spatial pattern and connectivity of urban green areas. My objective was to use a previously developed high spatial resolution ( $4 \mathrm{~m}$ ) classification to explore and highlight the potentially rich intra-urban vegetation variation that is generally overlooked in medium to moderate spatial resolution studies that have been performed for Puerto Rico. Additionally, I compared green cover features, including per capita green space, of San Juan to a sample of U.S. cities studied by Nowak and Greenfield (2012). This type of analysis will be useful to scientists and city managers involved in the study, operations, and future planning of land uses for this tropical city. The study also provides information about understudied urban systems in the tropics and will be useful for comparisons with temperate and boreal urban systems.

MSPA is a shape and connectivity detection algorithm that performs a pixel-by-pixel segmentation analysis of foreground objects against a background matrix (Soille and Vogt 2009). Given a set of user-defined parameters, including edge width and pixel connectivity rule, MSPA outputs a layer containing edge, core, and various connector classes of green areas for the user to interpret. The resulting pattern classes are mutually exclusive, and the analysis can be executed at any spatial scale (Vogt et al. 2007a, b).

Other national vegetation and green infrastructure assessments have used this type of spatial pattern analysis at regional scales with the National Land Cover Data at 30-m resolution (Wickham et al. 2010, Riitters 2011). The European Joint Forest Commission has developed integrated software called GUIDOS (Graphical User Interface for the Description of Image Objects and their Shapes), which incorporates the MSPA routines as well as other image processing and GIS tools to perform the spatial pattern analysis (GUIDOS 2012). All of these tools can improve the capacity of social-ecological scientists to conceptualize and analyze the role of green areas in urban environments. 


\section{METHODS}

\section{Study area}

The study area is the Municipality of San Juan, Puerto Rico $\left(18^{\circ}\right.$ $\left.27^{\prime} 00^{\prime \prime} \mathrm{N}, 66^{\circ} 04^{\prime} 00^{\prime \prime} \mathrm{W}\right)$, which comprises 12,734 ha. San Juan is a tropical and coastal city $>500$ years old that functions as the capital of Puerto Rico. More details on its social and ecological characteristics are provided by A. E. Lugo et al. (unpublished manuscript). For illustrative purposes, I display some of the results for the Río Piedras River watershed, which is a portion of the whole city but was the focus of the studies reported in this special issue (Fig. 1). Lugo et al. (2011) also provide details of the Río Piedras River watershed.

Fig. 1. Map of the green areas of the municipality of San Juan, Puerto Rico. The Río Piedras River watershed is highlighted in yellow.

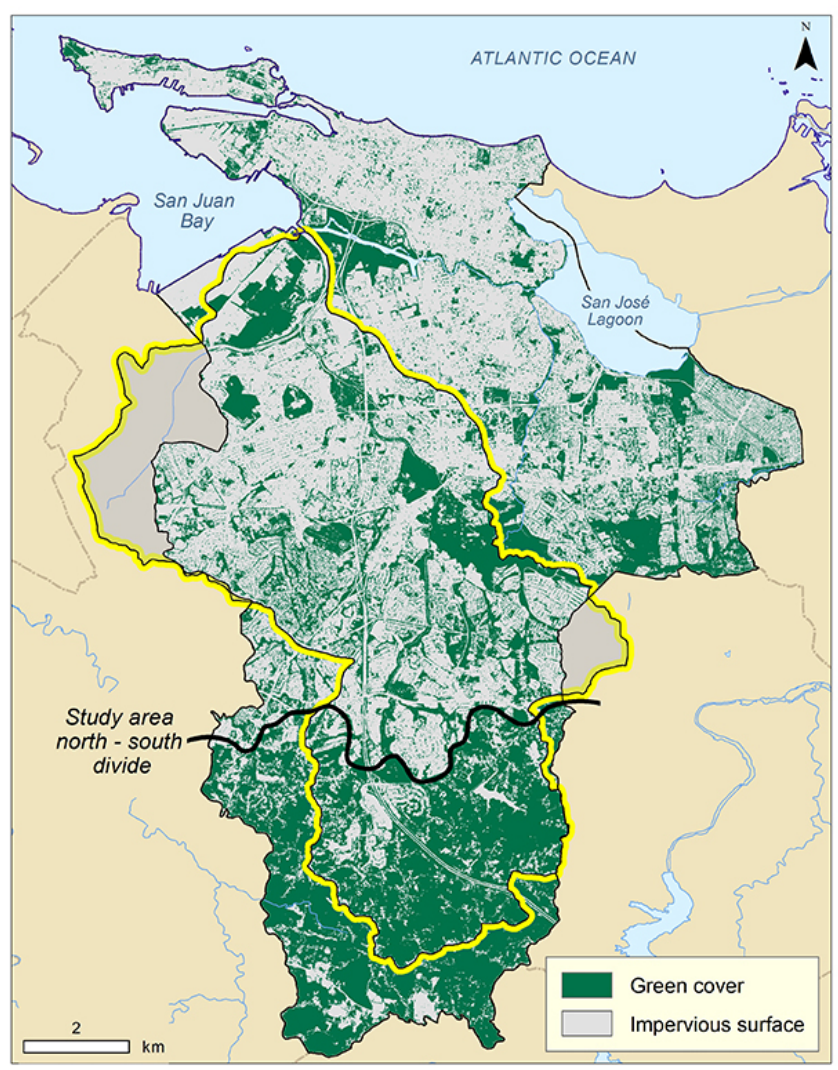

\section{Analysis layers}

I used a previously developed 2002 4-m resolution IKONOS landcover classification of the San Juan Metropolitan Area generated for the U.S. Department of Agriculture Forest Service (American Forests 2002). The land-cover classes included impervious surface, tree cover, pasture and grass, bare surface, and water. The dataset was clipped to fit the city of San Juan and co-registered to a 2004 U.S. Geological Survey urban high-resolution aerial orthophotoset. Using ArcMap 9.3.1 (ESRI 2009), I reclassified the land cover to produce two separate binary masks: a tree cover, and a combined tree and grass/pasture layer for green area characterization. Both masks were exported into geotiff format for spatial pattern detection.

\section{Spatial pattern analysis}

I downloaded and installed GUIDOS version 1.3 toolbox, which is available from the software homepage (http://forest.jrc.ec. europa.eu/download/software/guidos/). Among other image processing and GIS tools, the software contains the MSPA toolset used for processing the tree cover and green areas binary images. The algorithms of the software for this interface are based on concepts of mathematical morphological image analysis described in Soille and Vogt (2009).

For MSPA parameters, I used an edge width of four pixels (16 $\mathrm{m})$. This distance was selected by assessing how well the MSPA resulting layers matched known urban vegetation corridors in the vicinity of the Botanical Gardens (inside the Río Piedras River watershed), which other studies and the local community had already identified as green corridor resources (Rodríguez Mattei 2004). I also selected an eight-pixel foreground connectivity rule and chose to set transition pixels and intext toggle switches to "on" and "off", respectively. The GUIDOS user guide contains a full description of these parameters and how they affect the resulting images. Wickham et al. (2010) also provide ample discussion of the various MSPA parameters' effects for green infrastructure characterization.

The MSPA tool original output classes include core, islet, perforation, edge, branch, and various bridge and loop types (Table 1). Following Riitters (2011), I merged all bridge and loop pattern classes into a connector class to output six structural pattern categories. This was done to simplify the interpretation of results by using local-scale and contextual information for San Juan that I derived from the 2004 aerial orthophotos. In addition, I regionalized the results by San Juan Municipal Ordinance Plan (San Juan Municipality Office of Planning and Territorial Ordinance 2003) predominant classifications of urban lands in the northern sector of the city ("SU"), and southern upland rural lands designated for special protection ("SRC/SREP"), which mostly extend above the 100-m elevation divide (Fig. 1). Areal extents and percent of green and tree cover were calculated for each pattern class found (Table 2).

\section{City comparison and calculation of per capita green space}

To compare San Juan to other cities at similar temporal (circa 2002) and high-resolution spatial scales, I extracted land cover information for 20 U.S. cities studied by Nowak and Greenfield (2012). Year 1 percentages reported for grass/herb and tree/shrub land covers in Table 2 of Nowak and Greenfield (2012) were combined to obtain an overall green cover class percentage for each city. Similarly, all impervious surface cover classes were merged into one impervious surface percentage per city. These percentages were multiplied by the city land area $\left(\mathrm{km}^{2}\right)$ to estimate green and impervious surface cover extents. The resulting green cover area was converted to square-meters and divided by year 2000 U.S. census population data (U.S. Census Bureau 2000) to calculate per capita green space for each city. The results of these calculations were ordered by per capita green space for all 21 cities, including San Juan (Table 3). 
Table 1. Definition of the spatial patterns of green areas as defined by morphological spatial pattern analysis (MSPA) for this study, including the modifications of Riitters (2011).

\begin{tabular}{|c|c|c|}
\hline MSPA class & Spatial pattern description & Map color \\
\hline Background & $\begin{array}{l}\text { Background pixels in impervious, bare, } \\
\text { and sand land-cover categories }\end{array}$ & Gray \\
\hline Branch & $\begin{array}{l}\text { Foreground pixels connected to one edge } \\
\text { or one perforated spatial pattern class }\end{array}$ & Orange \\
\hline Connector & $\begin{array}{l}\text { Foreground pixels connecting two or } \\
\text { more core vegetation areas }\end{array}$ & Red \\
\hline Core & $\begin{array}{l}\text { Continuous foreground pixels with } \\
\text { distances greater than an edge width of } \\
\text { four pixels }(16 \mathrm{~m})\end{array}$ & Green \\
\hline Islet $\dagger$ & $\begin{array}{l}\text { Foreground pixels too small to contain } \\
\text { core, but not a connector or branch }\end{array}$ & Brown \\
\hline Edge & Exterior width around core pixels $(16 \mathrm{~m})$ & Black \\
\hline Perforated & $\begin{array}{l}\text { Interior edge pixels around core area } \\
\text { perforations }\end{array}$ & Blue \\
\hline
\end{tabular}

$\dagger$ This spatial pattern class was mostly associated with green areas in housing yards and alongside city streets or sidewalks. See Discussion.

Table 2. Land cover area for the municipality of San Juan, Puerto Rico, in 2002.

\begin{tabular}{|c|c|c|c|c|c|c|}
\hline \multirow[b]{2}{*}{ Land cover } & \multicolumn{2}{|c|}{ Entire city } & \multicolumn{2}{|c|}{ Northern sector } & \multicolumn{2}{|c|}{ Southern sector } \\
\hline & $\begin{array}{l}\text { Area } \\
\text { (ha) }\end{array}$ & $\begin{array}{c}\text { Area } \\
(\%)\end{array}$ & $\begin{array}{c}\text { Area } \\
\text { (ha) }\end{array}$ & $\begin{array}{c}\text { Area } \\
(\%)\end{array}$ & $\begin{array}{c}\text { Area } \\
\text { (ha) }\end{array}$ & $\begin{array}{c}\text { Area } \\
(\%)\end{array}$ \\
\hline Trees & 3356 & 26.4 & 1641 & 16.9 & 1715 & 56.9 \\
\hline $\begin{array}{l}\text { Grass or } \\
\text { pasture }\end{array}$ & 1949 & 15.3 & 1350 & 13.9 & 599 & 19.9 \\
\hline Impervious & 7049 & 55.4 & 6371 & 65.5 & 678 & 22.5 \\
\hline Bare & 36 & 0.3 & 34 & 0.3 & 2 & 0.1 \\
\hline Sand & 8 & 0.1 & 8 & 0.1 & 0 & 0 \\
\hline Water & 335 & 2.6 & 319 & 3.3 & 17 & 0.6 \\
\hline Entire city & 12,734 & 100 & 9723 & 100 & 3011 & 100 \\
\hline
\end{tabular}

Additionally, to visualize the similarities in green cover features among the various cities, nonmetric multidimensional scaling (NMS) ordination analysis was performed. I used all six variables from Table 3 for the analysis (i.e., land area, percent green cover, percent impervious cover, area of green cover, population density, and per capita green space). The ordination used the Sørensen distance to generate a two-dimensional solution in PC-Ord 6.0 software (McCune and Mefford 2011). NMS was chosen as an ordination method because it can robustly reduce multivariate data into low-dimensional space, thus assisting comparison among the city variables. This type of ordination also requires minimal assumptions about relationships among variables and is minimally affected by noise in the data (McCune and Grace 2002, Urban et al. 2002).

\section{RESULTS}

In 2002, the green areas of San Juan covered 5,305 ha or almost $42 \%$ of the municipality (Fig. 1, Table 2 ). Forests composed $26 \%$, and impervious surfaces 55\%, of San Juan's land area. The city had a clear geographic divide in the distribution of green and impervious surfaces, with a greater percentage of green areas in the southern portion of the city and a greater percentage of impervious cover in its northern sector (Table 2). In terms of areal extent, however, northern San Juan had 677 ha more green cover dispersed across the city than did the southern region (Fig. 1). This difference is mainly due to grass/pasture cover in the north, whereas forest cover predominates south of the city.

The morphological spatial pattern distribution of green areas revealed that most of the green areas were classified as core, followed by edges, islets, and connectors (Fig. 2). Branches and perforated green areas were less represented in the city. However, when the morphological spatial pattern distribution of forests was analyzed separately, the predominant landscape unit was edges, followed by core (Fig. 2). The predominant effect of green areas other than forests in the city was to enhance greatly the abundance of cores or continuous green areas.

Fig. 2. Amount of area covered by different spatial patterns of urban green areas and forests in San Juan, Puerto Rico. See Table 1 for definitions of spatial patterns.

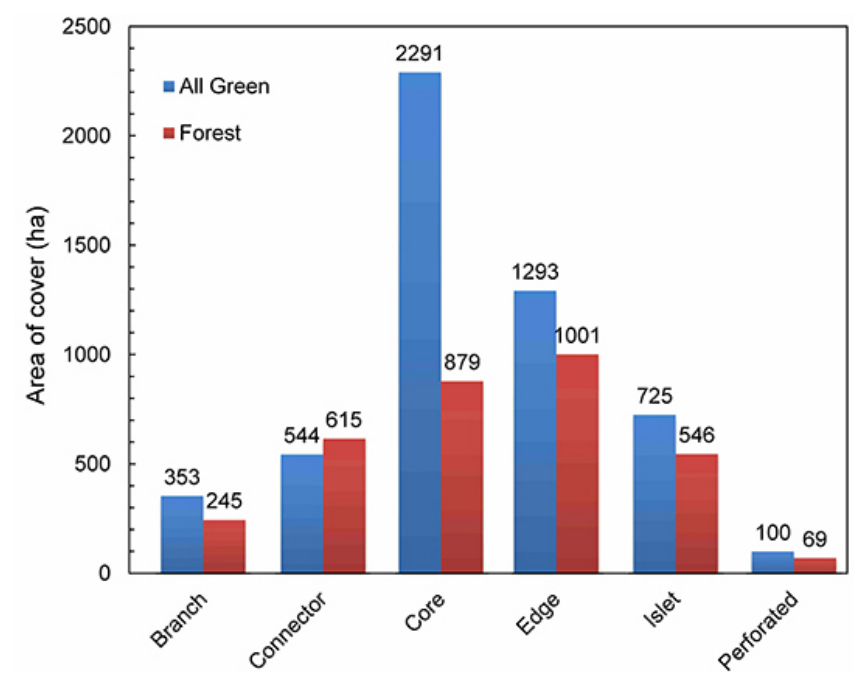

Analogous to the pattern of overall distribution of green area cover in San Juan (Fig. 1), the geographic distribution of landscape units showed a north/south divide (Fig. 3). Most core areas occurred on the southern portion of the city, whereas islets dominated the highly urbanized northern portion of the city (Fig. 4). For example, in the Country Club sector of San Juan, the importance of vegetation in house yards and street corridors is clearly visible, and islets had 3- and 2.5-times more area cover than did cores and edges, respectively (Fig. 4).

When compared to the 20 other cities used as references (Table 3), San Juan ranked in the bottom one-third (18th) in both land area $\left(127.3 \mathrm{~km}^{2}\right)$ and percent green cover $(41.7 \%)$. However, it had the fourth largest percentage of impervious surface $(55.4 \%)$ among the cities and was in the fifth position with regard to population density. In terms of per capita green space, the city occupied the 17 th position, with $122.2 \mathrm{~m}^{2} /$ inhabitant. The NMS 
Table 3. Land area characteristics of the city of San Juan compared to 20 other reference cities in the United States as determined by Nowak and Greenfield (2012). Population and land area data are taken from 2007 U.S. census data (U.S. Census Bureau 2008). The list is ranked from largest to smallest per capita green space. The city of San Juan is indicated in boldface font.

\begin{tabular}{|c|c|c|c|c|c|}
\hline City, state & Land area $\left(\mathrm{km}^{2}\right)$ & Green cover $(\%) \dagger$ & $\begin{array}{c}\text { Impervious surface } \\
\text { cover }(\%) \dagger\end{array}$ & $\begin{array}{c}\text { Green cover area } \\
\left(\mathrm{km}^{2}\right)\end{array}$ & $\begin{array}{l}\text { Per capita green } \\
\text { space }\left(\mathrm{m}^{2}\right)\end{array}$ \\
\hline Nashville, Tennessee & 1225.8 & 80.3 & 17.7 & 984.4 & 1804.4 \\
\hline Kansas City, Missouri & 812.0 & 79.9 & 18.2 & 648.8 & 1469.2 \\
\hline Atlanta, Georgia & 341.4 & 70.4 & 26.5 & 240.3 & 577.1 \\
\hline New Orleans, Louisiana & 467.8 & 56.9 & 41.4 & 266.2 & 549.1 \\
\hline Albuquerque, New Mexico & 467.8 & 49.9 & 35.3 & 233.4 & 520.6 \\
\hline Houston, Texas & 1500.6 & 60.4 & 37.9 & 906.4 & 463.1 \\
\hline Spokane, Washington & 149.7 & 49.5 & 33.8 & 74.1 & 378.8 \\
\hline Denver, Colorado & 397.3 & 52.3 & 40.0 & 207.8 & 375.3 \\
\hline Portland, Oregon & 347.8 & 54.2 & 43.2 & 188.5 & 356.3 \\
\hline Tacoma, Washington & 129.8 & 51.5 & 40.7 & 66.8 & 345.2 \\
\hline Pittsburgh, Pennsylvania & 144.0 & 59.0 & 40.0 & 85.0 & 253.9 \\
\hline Syracuse, New York & 65.0 & 50.0 & 50.0 & 32.5 & 221.9 \\
\hline Minneapolis, Minnesota & 142.2 & 54.7 & 42.9 & 77.8 & 203.2 \\
\hline Detroit, Michigan & 359.5 & 51.7 & 46.5 & 185.9 & 195.4 \\
\hline Baltimore, Maryland & 209.3 & 53.9 & 43.7 & 112.8 & 173.2 \\
\hline Los Angeles, California & 1215.0 & 43.3 & 52.2 & 526.1 & 142.4 \\
\hline San Juan, Puerto Rico $\dagger$ & 127.3 & 41.7 & 55.4 & 53.1 & 122.2 \\
\hline Boston, Massachusetts & 125.4 & 47.9 & 48.2 & 60.0 & 101.9 \\
\hline Miami, Florida & 92.5 & 38.6 & 60.0 & 35.7 & 98.5 \\
\hline Chicago, Illinois & 588.2 & 39.3 & 58.5 & 231.2 & 79.8 \\
\hline New York, New York & 785.5 & 37.5 & 59.8 & 294.6 & 36.2 \\
\hline
\end{tabular}

$\dagger$ With the exception of San Juan, land cover percentages are from Nowak and Greenfield (2012).

Fig. 3. Geographic distribution of green cover spatial patterns in San Juan, Puerto Rico, using morphological spatial pattern analysis (MSPA) classes.

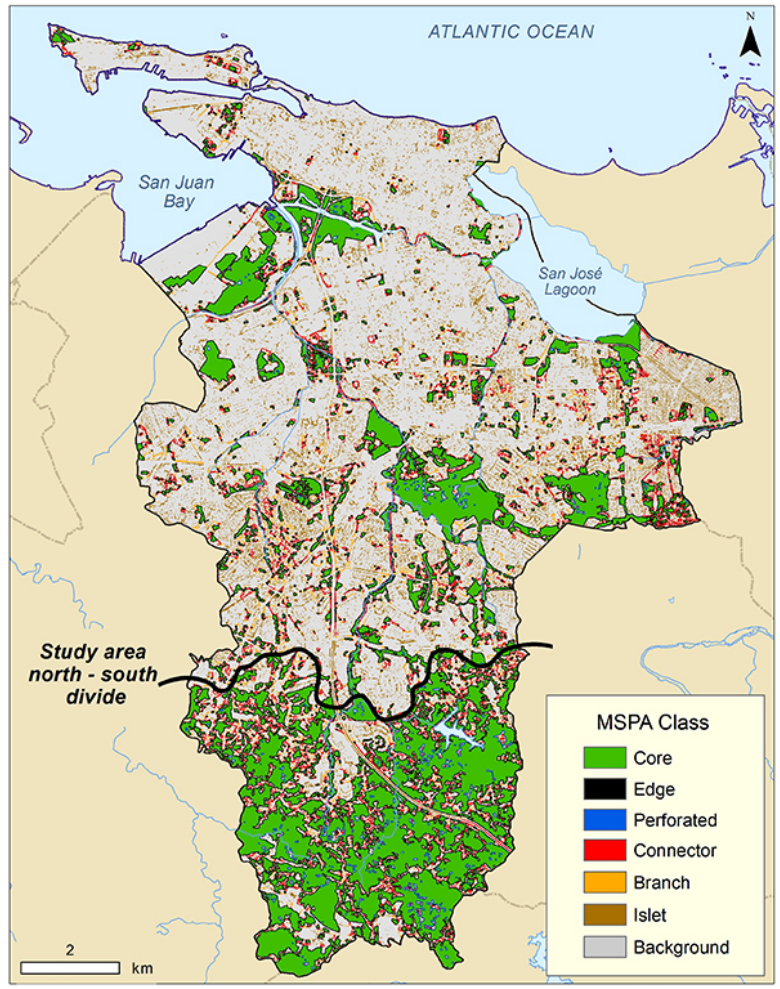

Fig. 4. Geographic distribution of green area spatial patterns in the Country Club sector of San Juan, Puerto Rico. The conspicuous abundance of islets mostly corresponds to the yards of individual households. Green areas along streets are also visible.

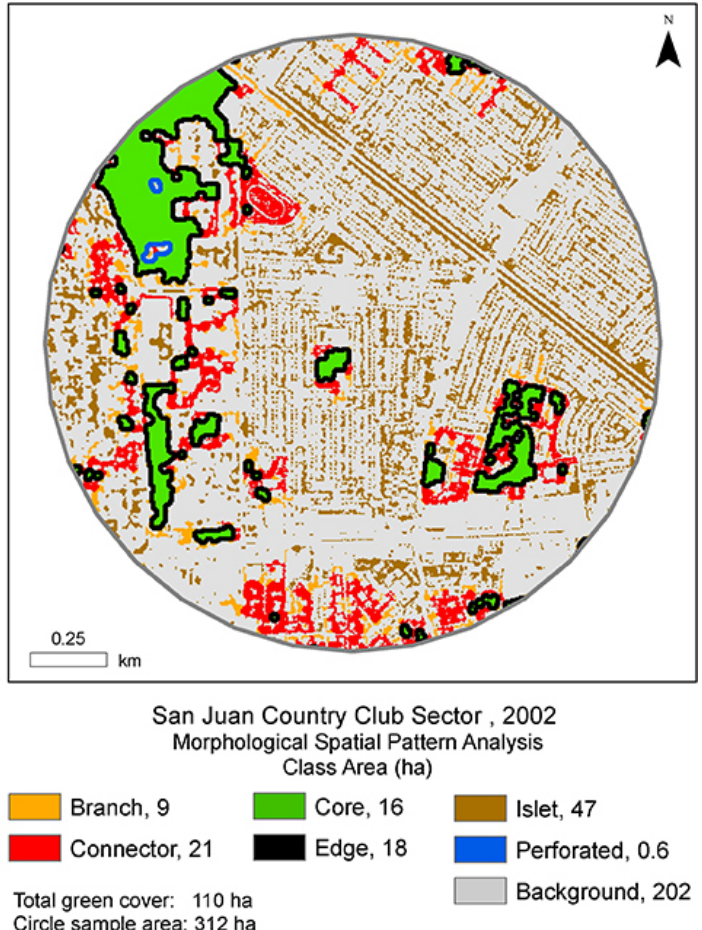


ordination space plotted San Juan in the grouping of cities that includes Syracuse, Pittsburgh, Minneapolis, Detroit, Baltimore, Miami, Boston, Chicago, and Los Angeles (Fig. 5). The cities of Baltimore, Miami, and Boston appear closer in similarity space to San Juan than do any others. Upon further examination of the variables, Baltimore, to the left of San Juan, is most comparable to the cities of Detroit, Minneapolis, Pittsburgh, and Syracuse in terms of percent and per capita green cover. Percent and per capita green space for Los Angeles plots close to San Juan also, yet land area and extent of green cover pulls this city farther away from other more similar cities. Miami and Boston remain then as the two cities with overall variable space closest to that of San Juan. When both land area and population density are taken into account (Table 3), San Juan is more comparable in percent and extent of green cover and per capita green space to Boston (101.9 $\mathrm{m}^{2} /$ inhabitant) than to Miami ( $98.5 \mathrm{~m}^{2} /$ inhabitant). Miami is $27 \%$ smaller in land area than San Juan, it is the closest geographically, and the only other city in the reference set seasonally exhibiting similar tropical climate characteristics. Cities with large land area and much higher population density such as Chicago and New York City show greater extents of green cover but, in contrast, lower per capita green space than San Juan.

Fig. 5. Nonmetric multidimensional scaling ordination of city green feature similarities generated using the Sørensen distance (McCune and Mefford 2006). Six variables were included in the analysis: land area, percent green cover, percent impervious cover, area of green cover, population density, and per capita green space (Table 3). The city of San Juan is indicated in boldface font.

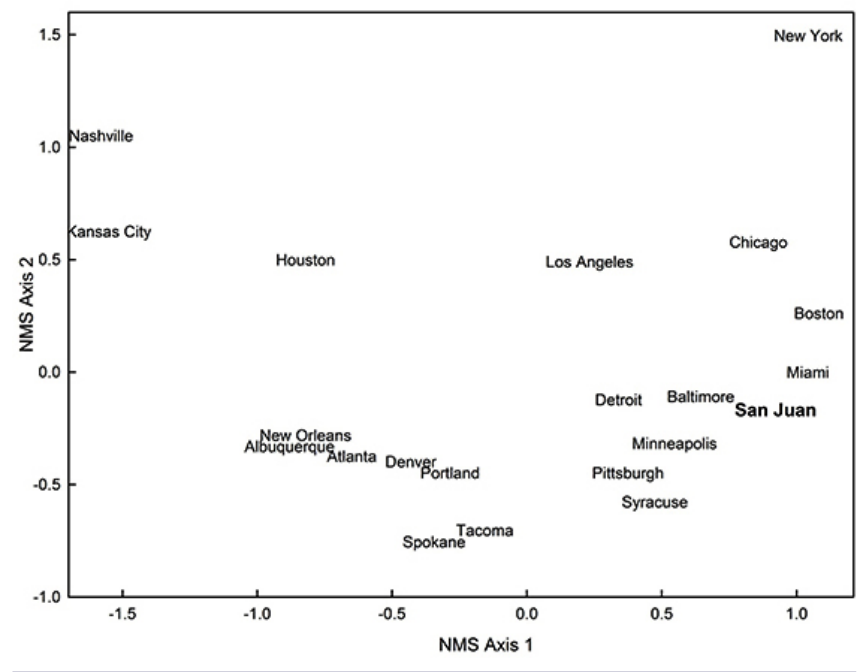

\section{DISCUSSION}

The use of a high-resolution image to assess the area and distribution of urban green areas uncovers a new perspective on the city of San Juan (Fig. 1). A previous analysis using Landsat $7 \mathrm{ETM}+$ imagery resulted in a green area cover of 4,203 ha, equivalent to $32 \%$ of the city (Lugo et al. 2011). I found $>1,000$ ha of additional green areas for a total green area cover in 2002 of almost $42 \%$ (Table 2). This increase is related to vegetation changes arising from 1999 to 2002, but also can be attributed to accuracy gains from using a finer image resolution classification because features become better delineated at 4-m resolution scale (Woodcock and Strahler 1987, Walton 2008, Walton et al. 2008). This increased accuracy highlights the importance of using high to very high resolution imagery for mapping urban green spaces at the cityscape level. Complex intra-urban vegetation of individual house yards and streets, particularly in areas usually classified as dense urban types, can be masked when moderateresolution imagery is used or when vector-based photointerpretation is employed. By using a pixel size of $4 \mathrm{~m}$, green infrastructure elements within the city neighborhoods become detectable. This includes groups of trees, individual tree crowns, and lawns along streets or alleys. These objects are all smaller than what a LANDSAT pixel could capture. A high-resolution spatial classification coupled to MSPA analysis helped to reveal how these locations support significant areas of vegetation whose importance for the city is discussed elsewhere in this special issue.

The results for green area cover based on high-resolution analysis highlight the importance of private ownership for the conservation of urban vegetation. Normally, the conservation of urban green areas is focused on large vegetation patches in protected urban areas or in public parks and other open spaces. In San Juan, individual yards collectively comprise a significant fraction of the total green infrastructure of the city. The MSPA islet class best represents this spatial pattern in housing yards and alongside city streets or sidewalks, and islets account for almost one-half of the extent of green cover for this sector of the city (Fig. 4). This vegetation functions in a number of ways as a provider of ecosystem services to urbanites and other organisms. However, the conservation of these green islets depends on the decisions of individual households, although Ramos Santiago et al. (2014) show that there might be a socioeconomic basis that influences which sectors of the city conserve these green areas and which do not. Nevertheless, understanding the significance of these islets to the greenness of the city opens new avenues of dialog and education concerning their importance and conservation value.

MSPA also helped to delineate better the intra-urban pattern features of the green spaces within San Juan. The knowledge gathered allows city planners to visualize green cores, corridors, and islets within what is normally termed dense urban cover. The classification itself implies functionality at the landscape level. Examples of functionality would be the connector role of corridors or the internal synergy of core vegetation relative to islets. Dense urban cover does not necessarily mean $100 \%$ impermeable surfaces. San Juan, with a large portion of its land covered with impervious surfaces (Table 2), is an example of how even with a high level of impermeable surfaces, opportunities exist for managing vegetation. The tropical climate of the city and the resulting rapid rates of vegetation growth and succession contribute to rapid expansion of green cover when lots are abandoned or soil is exposed. Thus, the ecological conditions of the city provide managers with the option of incorporating green infrastructure designs into city development or land re-purposing schemes. Beyond the city's Territorial Ordinance Plan, San Juan could benefit from developing a comprehensive green infrastructure strategy to sustain and expand its green urban cover to take advantage of the ecosystem services these green spaces can provide to its inhabitants. 
When San Juan is compared to other reference cities across the United States (Nowak and Green 2012), I found that for all of the green cover features, San Juan is positioned within the bottom one-third of the list (Table 3). Additionally, green area characteristics are closely similar to those of two other Atlantic port cities, Boston and Miami. Despite its small land area, it is worth mentioning that in terms of percent impervious surface, San Juan ranks fourth among cities with large land area such as Chicago and New York City. An analogous pattern was found for population density, where San Juan occupies the fifth position, with Boston and Miami just above San Juan in this regard. Nevertheless, per capita green space for the city of San Juan leads this group of cities, with $122.2 \mathrm{~m}^{2}$ per capita. The calculation of this last value is particularly useful as a measure of sustainability to compare the city of San Juan across time and with other cities across the globe. Future studies following these trends should continue to increase the knowledge about this tropical city.

Green infrastructure in San Juan was already quite wide-ranging in 2002 (Figs. 1-4), and the urban population has been contributing to this development through the management of yards for aesthetics and food production (Garcia-Montiel et al. 2014, Meléndez-Ackerman et al. 2014). These results serve as a starting point for green infrastructure mapping and landscape pattern analysis of the urban green spaces within the city of San Juan. The effectiveness of both research and city planning will be further enhanced as a result of this type of finer-scale urban cover exploration.

Responses to this article can be read online at: http://www.ecologyandsociety.org/issues/responses. php/6598

\section{Acknowledgments:}

This study was done in cooperation with the University of Puerto Rico. Special thanks to co-workers Ariel E. Lugo, Tamara Heartsill, and Magaly Figueroa, and to colleagues Sebastián Martinuzzi (University of Wisconsin-Madison) and Sandra Molina Colón (Pontifical Catholic University of Puerto Rico) for their contributions to this article. This work is part of the USDA Forest Service contribution to the National Science Foundation San Juan Urban Long-Term Research Area Exp. (0948507) Grant to the Puerto Rico Conservation Foundation. Any opinions, findings, and conclusions or recommendations expressed in this material are those of the authors and do notnecessarily reflect the views of the National Science Foundation.

\section{LITERATURE CITED}

American Forests. 2002. Urban ecosystem analysis San Juan, Puerto Rico Metropolitan area: calculating the value of nature. Report to USDA Forest Service International Institute of Tropical Forestry, Rio Piedras, Puerto Rico.

Breuste, J., H. Feldmann, and O. Uhlmann, editors. 1998. Urban ecology. Springer, Berlin, Germany. http://dx.doi. org/10.1007/978-3-642-88583-9
Breuste, J., J. Niemelä, and R. P. H. Snep. 2008. Applying landscape ecological principles in urban environments. Landscape Ecology 23(10):1139-1142. http://dx.doi.org/10.1007/s10980-008-9273-0

Dige, G. 2011. Green infrastructure and territorial cohesion. The concept of green infrastructure and its integration into policies using monitoring systems. Technical Report 18. European Environment Agency, Copenhagen, Denmark. [online] URL: http://www.eea. europa.eu/publications/green-infrastructure-and-territorial-cohesion.

ESRI. 2009. ArcGIS software version 9.3.1. Environmental Systems Research Institute, Redlands, California, USA.

Garcia-Montiel, D. C., J. C. Verdejo-Ortiz, R. SantiagoBartolomei, C. P. Vila-Ruiz, L. Santiago, and E. MelendezAckerman. 2014. Food sources and accessibility and waste disposal patterns across an urban tropical watershed: implications for the flow of materials and energy. Ecology and Society 19(1): 37. http://dx.doi.org/10.5751/ES-06118-190137

GUIDOS. 2012. Graphical user interface for the description of image objects and their shapes version 1.3. Institute for Environment and Sustainability, European Commission Joint Research Center, Ispra, Italy. [online] URL: http://forest.jrc.ec. europa.eu/download/software/guidos/.

Hudeková, Z. 2011. Assessing vulnerability to climate change and adapting through green infrastructure. GRaBS Expert Paper 7. Town and Country Planning Association and European Union, London, UK. [online] URL: http://www.grabs-eu.org/downloads/ EP7\%20FINAL.pdf.

Lugo, A. E., O. M. Ramos González, and C. Rodríguez Pedraza. 2011. The Río Piedras watershed and its surrounding environment. FS-980. USDA Forest Service, Washington, D.C., USA. [online] URL: http://www.fs.fed.us/global/iitf/pubs/RioPiedras FNLrvsd. pdf.

McCune, B., and J. B. Grace. 2002. Analysis of ecological communities. MjM Software, Gleneden Beach, Oregon, USA.

McCune, B., and M. J. Mefford. 2011. PC-ORD version 6.0. Multivariate analysis of ecological data. MjM Software, Gleneden Beach, Oregon, USA.

McDonnell, M. J., A. K. Hahs, and J. H. Breuste, editors. 2009. Ecology of cities and towns: a comparative approach. Cambridge University Press, Cambridge, UK. http://dx.doi.org/10.1017/ CBO9780511609763

Meléndez-Ackerman, E., R. Santiago, C. Vila, L. Santiago, J. Verdejo, D. Garcia-Montiel, H. Manrique, and E. HernandezCalo. 2014. Social-economic drivers of yard sustainable practices in a tropical city: testing the generality of bottom up vs. top down drivers. Ecology and Society. Ecology and Society 19(3): 20. http:// dx.doi.org/10.5751/ES-06563-190320

Niemelä, J., editor. 2011. Urban ecology: patterns, processes, and applications. Oxford University Press, Oxford, UK. http://dx.doi. org/10.1093/acprof:oso/9780199563562.001.0001

Nowak, D. J., and E. J. Greenfield. 2012. Tree and impervious cover change in U.S. cities. Urban Forestry and Urban Greening 11(1):21-30. http://dx.doi.org/10.1016/j.ufug.2011.11.005 
Ramos-Santiago, L. E., L. Villanueva-Cubero, L. E. SantiagoAcevedo, and Y. N. Rodriguez-Melendez. 2014. Green area loss in San Juan's inner-ring suburban neighborhoods: a multidisciplinary approach to analyzing green/gray area dynamics. Ecology and Society 19(2): 4. http://dx.doi.org/10.5751/ ES-06219-190204

Riitters, K. H. 2011. Spatial patterns of land cover in the United States: a technical document supporting the Forest Service 2010 RPA assessment. General Technical Report SRS-136. U.S. Department of Agriculture Forest Service, Asheville, North Carolina, USA. [online] URL: http://www.treesearch.fs.fed.us/ pubs/37766.

Rodríguez Mattei, M. T. 2004. Plan conceptual para el desarrollo de un corredor verde multiusos en Río Piedras. Thesis. University of Puerto Rico, Río Piedras, Puerto Rico.

San Juan Municipality Office of Planning and Territorial Ordinance. 2003. San Juan Territorial Ordinance Plan: Memorial, volume 3. San Juan Municipality Office of Planning and Territorial Ordinance, San Juan, Puerto Rico.

Science for Environment Policy. 2012. The multifunctionality of green infrastructure. European Commission Directorate-General Environment, Bristol, UK. [online] URL: http://ec.europa.eu/ environment/nature/ecosystems/docs/Green Infrastructure.pdf.

Soille, P., and P. Vogt. 2009. Morphological segmentation of binary patterns. Pattern Recognition Letters 30(4):456-459. http:// dx.doi.org/10.1016/j.patrec.2008.10.015

Urban, D., S. Goslee, K. Pierce, and T. Lookingbill. 2002. Extending community ecology to landscapes. Ecoscience 9 (2):200-202.

U.S. Census Bureau. 2008. County and city data book: 2007. Table $C-1$. Department of Commerce, Economics, and Statistics Administration, Washington, D.C., USA. [onlin] URL: http:// www.census.gov/prod/2008pubs/07ccdb/tabc.pdf.

Vogt, P., K. H. Riitters, C. Estreguil, J. Kozak, T. G. Wade, and J. D. Wickham. 2007a. Mapping spatial patterns with morphological image processing. Landscape Ecology 22 (2):171-177. http://dx.doi.org/10.1007/s10980-006-9013-2

Vogt, P., K. H. Riitters, M. Iwanowski, C. Estreguil, J. Kozak, and P. Soille. 2007b. Mapping landscape corridors. Ecological Indicators 7(2):481-488. http://dx.doi.org/10.1016/j.ecolind.2006.11.001

Walton, J. T. 2008. Difficulties with estimating city-wide urban forest cover change from national, remotely-sensed tree canopy maps. Urban Ecosystems 11(1):81-90. http://dx.doi.org/10.1007/ $\underline{\text { s11252-007-0040-9 }}$

Walton, J. T., D. J. Nowak, and E. J. Greenfield. 2008. Assessing urban forest canopy cover using airborne or satellite imagery. Arboriculture and Urban Forestry 34(6):334-340. [online] URL: http://joa.isa-arbor.com/request.asp?JournalID=1\&ArticleID=3069\&Type $=2$.

Wickham, J. D., K. H. Riitters, T. G. Wade, and P. Vogt. 2010. A national assessment of green infrastructure and change for the conterminous United States using morphological image processing. Landscape and Urban Planning 94(3-4):186-195. http://dx.doi.org/10.1016/j.landurbplan.2009.10.003
Woodcock, C. E., and A. H. Strahler. 1987. The factor of scale in remote sensing. Remote Sensing of Environment 21(3):311-332. http://dx.doi.org/10.1016/0034-4257(87)90015-0 